\title{
Paecilomyces Rot: A New Apple Disease
}

Megan N. Biango-Daniels ${ }^{\dagger}$ and Kathie T. Hodge, Section of Plant Pathology and Plant-Microbe Biology, School of Integrative Plant Science, Cornell University, Ithaca, NY 14853

\begin{abstract}
Paecilomyces niveus is an important food spoilage fungus that survives thermal processing in fruit products, where it produces the mycotoxin patulin. Spoilage of products has been attributed to soil contamination; however, little is known about the ecology of this organism. In this study, orchard soils and culled apple fruit were surveyed and the ability of $P$. niveus to infect apple was tested on two popular apple varieties. $P$. niveus was found in $34 \%$ of sampled orchard soils from across New York. Completing Koch's postulates, $P$. niveus was demonstrated to cause postharvest disease in Gala and Golden Delicious apple. Symptoms of this disease, named Paecilomyces rot, resemble several other apple diseases, including

black rot, bitter rot, and bull's-eye rot. External symptoms of Paecilomyces rot include brown, circular, concentrically ringed lesions, with an internal rot that is firm and cone-shaped. Both Gala and Golden Delicious apple fruit inoculated with $P$. niveus developed lesions $\geq 43 \mathrm{~mm}$ in size at 22 days after inoculation. There is some evidence that the size of lesions and rate of infection differ between Gala and Golden Delicious, which may indicate differing resistance to $P$. niveus. This work shows that $P$. niveus is common in New York orchard soil and can cause a novel postharvest fruit disease. Whether infected fruit can serve as an overlooked source of inoculum in heat-processed apple products requires further study.
\end{abstract}

Paecilomyces niveus Stolk \& Samson (Byssochlamys nivea Westling) (Ascomycota, Eurotiomycetes, Eurotiales, Thermoascaceae) is an important food spoilage fungus (Houbraken and Samson 2017). It causes disintegration of thermally processed foods while on the shelf, and can produce the federally regulated mycotoxin patulin (Houbraken et al. 2006; Puel et al. 2010; Sant'Ana et al. 2008). Not only does it produce conidia and chlamydospores but, being homothallic, it also readily produces abundant, durable ascospores that can survive high heat (Samson et al. 2009). Ascospores of $P$. niveus can survive temperatures of $90^{\circ} \mathrm{C}$, leading to spoilage of thermally processed syrups and canned fruit (Beuchat and Toledo 1977; Tournas 1994). This hard-to-kill species and its relatives in the genus Paecilomyces grow in harsh conditions, including on leather, in alcohol, and under low-oxygen conditions (Beuchat and Rice 1979; Beuchat and Toledo 1977; Brown and Smith 1957; Taniwaki et al. 2009, 2010).

$P$. niveus can grow in apple products containing up to $40 \mathrm{~g}$ of added sucrose per $100 \mathrm{ml}$ (40\% weight by volume) and at a water activity of 0.92 (Beuchat and Toledo 1977). A water activity this low inhibits the growth of most other spoilage organisms by limiting the water availability and creating an osmotic gradient that dehydrates growing fungi (Beuchat and Toledo 1977; Grant 2004). Spoilage of thermally processed foods by $P$. niveus has been speculated to result from soil contamination (Brown and Smith 1957; King et al. 1969). The fungus has been found in orchard soils and on decaying fruit and vegetable matter but its ecology is not well understood (Beuchat and Rice 1979; Splittstoesser et al. 1971).

${ }^{\dagger}$ Corresponding author: M. N. Biango-Daniels; E-mail: mnd24@ cornell.edu

Funding: This work was supported by the United States Department of Agriculture National Institute of Food and Agriculture, Hatch project 1002546, and by a Cornell CALS Arthur Boller Apple Research Grant.

Any opinions, findings, conclusions, or recommendations expressed in this publication are those of the authors and do not necessarily reflect the view of the National Institute of Food and Agriculture (NIFA) or the United States Department of Agriculture (USDA).

*The $\boldsymbol{e}$-Xtra logo stands for "electronic extra" and indicates that one supplementary figure is published online.

Accepted for publication 23 February 2018.

(C) 2018 The American Phytopathological Society
One clue to the ecology of $P$. niveus may be its production of patulin, which is not only a mycotoxin but also a well-established virulence factor. It enhances the ability of the distantly related fungus Penicillium expansum to invade apple fruit (Sanzani et al. 2012; Snini et al. 2014), leading to Penicillium blue mold rot, an important postharvest disease of apple. Some studies have raised questions about the potential of Paecilomyces niveus to act as an apple pathogen, which could give it a direct route into apple-based foods (Dombrink-Kurtzman and Engberg 2006; Salomão et al. 2014; Splittstoesser et al. 1971).

This study aimed to elucidate the ecology of $P$. niveus. A selective isolation protocol was used to survey for it in orchard soils and culled apple fruit, and the ability of $P$. niveus to act as a postharvest pathogen of apple was tested.

\section{Materials and Methods}

Identification methods. Putative isolates of $P$. niveus were morphologically identified using the Ascomycete key developed by Samson et al. (2000). To distinguish $P$. niveus from closely related species, genomic DNA was extracted and the internal transcribed spacer (ITS) region of the ribosomal DNA (rDNA), or the BenA region of the $\beta$-tubulin gene was amplified and sequenced. Mycelium was harvested from $P$. niveus cultures grown on potato dextrose agar (PDA; Criterion). Genomic DNA was extracted using the PowerSoil DNA Isolation Kit (MoBio), following the recommended protocol, and stored in elution buffer at $-20^{\circ} \mathrm{C}$. Genomic DNA was the target for polymerase chain reaction (PCR) amplification of the ITS region of the rDNA repeat, a widely accepted barcode for fungi, using forward ITS5 (5'-GGAGTAAAAGTCGTAACAAGG-3') and reverse ITS4 (5'-TCCTCCGCTTATTGATATGC-3') primers (Schoch et al. 2012; White et al. 1990). The BenA region of the $\beta$-tubulin gene was amplified using forward Bt2a (5'-GGTAACCAAATCGGTG CTGCTTTC- $\left.3^{\prime}\right)$ and reverse Bt2b (5'-ACCCTCAGTGTAGTGAC CCTTGGC-3') primers (Visagie et al. 2014).

Sigma-Aldrich REDTaq genomic DNA polymerase with $\mathrm{MgCl}_{2}$ was used in a DNA Engine PTC-200 thermal cycler (MJ Research). The ITS amplification was programmed as follows: initial denaturation at $95^{\circ} \mathrm{C}$ for $2 \mathrm{~min}$; then, 26 cycles of $94^{\circ} \mathrm{C}$ for $1 \mathrm{~min}, 55^{\circ} \mathrm{C}$ for $1 \mathrm{~min}$, and $72^{\circ} \mathrm{C}$ for $3 \mathrm{~min}$; and final extension of $72^{\circ} \mathrm{C}$ for $15 \mathrm{~min}$. The BenA region was amplified using a program of initial denaturation at $95^{\circ} \mathrm{C}$ for $2 \mathrm{~min}$; then, 30 cycles of $94^{\circ} \mathrm{C}$ for $1 \mathrm{~min}, 57^{\circ} \mathrm{C}$ for $1 \mathrm{~min}$, and $72^{\circ} \mathrm{C}$ for $3 \mathrm{~min}$; and final extension of $72^{\circ} \mathrm{C}$ for $15 \mathrm{~min}$. PCR amplicons were cleaned with the E.N.Z.A. Cycle-Pure kit (Omega Bio-tek), following the manufacturer's instructions. Amplicons were sequenced with the forward PCR primers, using an Applied Biosystems Automated 3730xl DNA analyzer, at the Cornell University Biotechnology 
Resource Center. The sequences were compared with reference sequences at the National Center for Biotechnology Information (NCBI) using BLASTn (Agostino 2012; Altschul et al. 1990), and they were subject to phylogenetic analyses.

Phylogenetic analyses. To confirm morphological identification of isolates and place them phylogenetically, two phylogenetic analyses were conducted, one using the partial $\beta$-tubulin alone and the other using a concatenation of the partial $\beta$-tubulin and ITS regions for isolate $\mathrm{CO} 7$ (this study). The identities of isolates used in this study were inferred by comparing their phylogenetic relationship with those of Samson et al. (2009). Accession numbers provided by Houbraken et al. (2008) and Samson et al. (2009) were used to acquire sequences for the partial $\beta$-tubulin and ITS regions from NCBI GenBank (Table 1). Only isolate sequences that were used in partial $\beta$-tubulin and ITS region tree construction of Samson et al. (2009) were used in the phylogenetic analysis (Table 1), apart from P. fulvus
(B. fulva) CBS 113954, for which only the partial $\beta$-tubulin sequence was included.

For the partial $\beta$-tubulin analysis, sequences from putative $P$. niveus isolates generated in this study were aligned to those used by Samson et al. (2009) using MUSCLE (Edgar 2004) via the EMBL-EBI online bioinformatics resource ( $\mathrm{Li}$ et al. 2015), with poorly aligned, divergent regions trimmed from the alignment using GBlocks, version $0.91 \mathrm{~b}$ (Castresana 2000), specifying the less stringent criteria. The total numbers of taxa and characters in the partial $\beta$-tubulin analysis were 47 and 437 , respectively. For the concatenated partial $\beta$-tubulin and ITS region analysis, the partial $\beta$-tubulin and ITS regions of isolate $\mathrm{CO} 7$ (this study) were aligned to those isolates used by Samson et al. (2009), for which both gene sequences were available. Each alignment was subsequently trimmed, as previously described. The partial $\beta$-tubulin and ITS region alignments were concatenated using SequenceMatrix, v1.8 (Vaidya et al. 2011). The total numbers of taxa and characters in

Table 1. Table of isolates and accession numbers used in phylogenetic analyses ${ }^{\mathrm{a}}$

\begin{tabular}{|c|c|c|c|c|}
\hline Species identification & Isolate & Source & ITS $^{\mathbf{b}}$ & $\beta$-tubulin \\
\hline Byssochlamys fulva & CBS 113954 & Samson et al. 2009 & 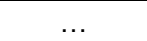 & FJ389985 \\
\hline B. fulva & CBS 132.33 & Samson et al. 2009 & FJ389939 & FJ389988 \\
\hline B. fulva & CBS 135.62 & Samson et al. 2009 & FJ389943 & FJ389989 \\
\hline B. fulva & CBS 146.48 & Samson et al. 2009 & FJ389940 & FJ389986 \\
\hline B. fulva & CBS 604.71 & Samson et al. 2009 & FJ389941 & FJ389997 \\
\hline B. lagunculariae & CBS 110378 & Samson et al. 2009 & FJ389946 & FJ390006 \\
\hline B. lagunculariae & CBS 373.70 & Samson et al. 2009 & FJ389944 & FJ389995 \\
\hline B. lagunculariae & CBS 696.95 & Samson et al. 2009 & FJ389945 & FJ389996 \\
\hline B. nivea & CBS 100.11 & Samson et al. 2009 & FJ389934 & FJ389999 \\
\hline B. nivea & CBS 113245 & Samson et al. 2009 & FJ389936 & FJ389998 \\
\hline B. nivea & CBS 133.37 & Samson et al. 2009 & FJ389935 & FJ390000 \\
\hline Paecilomyces niveus & $\mathrm{CO} 7$ & This study & MG008851 & MG008852 \\
\hline$P$. niveus & $100-10$ & This study & $\ldots$ & MG008853 \\
\hline$P$. niveus & $101-3$ & This study & $\ldots$ & MG008854 \\
\hline P. niveus & $102-1$ & This study & $\ldots$ & MG008855 \\
\hline$P$. niveus & $104-22$ & This study & $\ldots$ & MG008856 \\
\hline$P$. niveus & $106-3$ & This study & $\ldots$ & MG008857 \\
\hline$P$. niveus & $107-1$ & This study & $\ldots$ & MG008858 \\
\hline$P$. niveus & $108-11$ & This study & $\ldots$ & MG008859 \\
\hline$P$. niveus & $109-21$ & This study & $\ldots$ & MG008860 \\
\hline$P$. niveus & $110-3$ & This study & $\cdots$ & MG008861 \\
\hline$P$. niveus & $111-1$ & This study & $\ldots$ & MG008862 \\
\hline$P$. niveus & $112-22$ & This study & $\ldots$ & MG008863 \\
\hline$P$. niveus & $125-31$ & This study & $\ldots$ & MG008864 \\
\hline$P$. niveus & $140-11$ & This study & $\ldots$ & MG008865 \\
\hline P. niveus & $141-11$ & This study & $\ldots$ & MG008866 \\
\hline P. niveus & $146-311$ & This study & $\ldots$ & MG008867 \\
\hline B. spectabilis & CBS 101075 & Houbraken et al. 2008 & EU037051 & EU037069 \\
\hline B. spectabilis & CBS 102.74 & Houbraken et al. 2008 & EU037055 & EU037073 \\
\hline B. spectabilis & CBS 121581 & Houbraken et al. 2008 & EU037062 & EU037080 \\
\hline B. spectabilis & CBS 338.51 & Samson et al. 2009 & FJ389930 & FJ390007 \\
\hline B. zollerniae & CBS 374.70 & Samson et al. 2009 & FJ389933 & FJ390008 \\
\hline P. brunneolus & CBS 370.70 & Houbraken et al. 2008 & EU037050 & EU037068 \\
\hline P. divaricatus & CBS 110429 & Samson et al. 2009 & FJ389932 & FJ389991 \\
\hline P. divaricatus & CBS 284.48 & Samson et al. 2009 & FJ389931 & FJ389992 \\
\hline P. formosus & CBS 113247 & Samson et al. 2009 & FJ389921 & FJ390009 \\
\hline P. formosus & CBS 296.93 & Samson et al. 2009 & FJ389928 & FJ389994 \\
\hline P. formosus & CBS 371.70 & Samson et al. 2009 & FJ389920 & FJ389982 \\
\hline P. formosus & CBS 372.70 & Samson et al. 2009 & FJ389926 & FJ389990 \\
\hline P. formosus & CBS 628.66 & Samson et al. 2009 & FJ389927 & FJ389983 \\
\hline P. formosus & CBS 990.73B & Samson et al. 2009 & FJ389929 & FJ389993 \\
\hline P. saturatus & CBS 251.55 & Samson et al. 2009 & FJ389951 & FJ390002 \\
\hline P. saturatus & CBS 323.34 & Samson et al. 2009 & FJ389947 & FJ390005 \\
\hline P. saturatus & CBS 368.70 & Samson et al. 2009 & FJ389948 & FJ390001 \\
\hline P. saturatus & CBS 492.84 & Samson et al. 2009 & FJ389949 & FJ390003 \\
\hline P. saturatus & CBS 990.73A & Samson et al. 2009 & FJ389950 & FJ390004 \\
\hline Thermoascus crustaceus & CBS 181.67 & Samson et al. 2009 & FJ389925 & FJ389981 \\
\hline
\end{tabular}

${ }^{a}$ All CBS isolate identifications are per table 1 in Samson et al. (2009). Species identifications for isolates derived in the present study are based on phylogenetic affiliation with those of P. niveus (B. nivea) sensu Samson et al. (2009).

${ }^{\mathrm{b}}$ Internal transcribed spacer. 
the concatenated partial $\beta$-tubulin and ITS region analysis were 31 and 984 , respectively.

For both the partial $\beta$-tubulin and the concatenated partial $\beta$-tubulin and ITS region analyses, trees were constructed by Bayesian inference using MrBayes, v3.2.6 (Ronquist et al. 2012). The partial $\beta$-tubulin analysis was conducted using a $\mathrm{K} 80+\mathrm{G}$ model, selected by jModelTest 2.1 (Darriba et al. 2012) with the Bayesian information criterion. The Bayesian model averaging approach of rjMCMC was applied to the concatenated partial $\beta$-tubulin and ITS region analyses (Huelsenbeck et al. 2004). In the concatenated analysis, each gene was considered a separate partition, allowing for independent estimation of substitution rates, character state frequencies, gamma shape distributions, and proportions of invariable sites per partition. Posterior probabilities at branch nodes were inferred using two runs of 1,000,000 generations, with $25 \%$ burn-in. Phylogenetic trees were visualized in R, v3.4.2, using the Ape package (Paradis et al. 2004) in the RStudio v1.1.383 environment, rooted with Thermoascus crustaceus as the outgroup.

Detection of $\boldsymbol{P}$. niveus in New York orchard soil. To determine whether $P$. niveus was present in New York state orchard soils, in summer 2016, soil samples were taken from the top 6 in. $(15.24 \mathrm{~cm})$ of soil in orchards across the state by Cornell Cooperative Extension agents and independent consultants. This depth was chosen because it represents the soil that may contact apple fruit during harvest or if they are on the ground. Soils were sampled and mailed to Cornell University, refrigerated $\left(4^{\circ} \mathrm{C}\right)$ upon receipt, and processed within 2 weeks. In total, 32 different orchards were sampled across New York state. Due to miscommunication, four of the orchards were sampled in multiple places, which led to 48 soil samples being received by the Hodge Lab.

Soils were thermally processed by mixing them with sterile deionized (DI) water $(1: 2, \mathrm{wt} / \mathrm{vol})$. The resulting dilute soil samples were placed in 2-ml microcentrifuge tubes and heated in a water bath at $70^{\circ} \mathrm{C}$ for $30 \mathrm{~min}$. This process reduces the number of microorganisms present and has been shown to increase germination of $P$. niveus ascospores (Splittstoesser et al. 1970). For each cooled sample, $200 \mu \mathrm{l}$ was spread with a sterile L-shaped rod on five PDA Petri plates $(90 \mathrm{~mm})$ supplemented with streptomycin sulfate at $30 \mu \mathrm{g} \mathrm{ml}^{-1}$. After a 3-week incubation at $25^{\circ} \mathrm{C}$, all emerging colonies with a morphology consistent with $P$. niveus were subcultured on PDA at $25^{\circ} \mathrm{C}$ (Beuchat and Pitt 2001). As described above, isolates were morphologically identified and the identity was confirmed by phylogenetic analysis of sequences of the BenA region of the partial $\beta$-tubulin gene, a recognized fungal barcode that differentiates closely related species of Paecilomyces (Schoch et al. 2012).

Isolation of $P$. niveus from culled apple fruit. In addition to surveying for $P$. niveus in orchard soils, stored apple fruit with signs of postharvest diseases were sampled to detect any $P$. niveus present. In spring 2017, Cornell Orchards staff selected apple fruit displaying symptoms of postharvest diseases as bins were pulled from cold storage. Cornell Orchards, located in Ithaca, NY, is a teaching and retail facility that grows apple for fresh-market and cider production. The apple fruit, which were cultivars Mutsu, Goldrush, Empire, and Shizuka, had been stored at $1{ }^{\circ} \mathrm{C}$ since harvest the previous autumn.

Each week for 5 weeks, a 5-gal. (18.9 liter) bucket of culled apple fruit was received and apple lesions were dissected to harvest infected tissue. To reduce the possibility of surface soil contaminants, apple fruit were first surface sanitized with $70 \%$ ethanol. The pooled weekly sample, weighing between 40 and $51 \mathrm{~g}$, was frozen and stored at $-20^{\circ} \mathrm{C}$ for 2 to 3 months. Additionally, a separate sample from an apple, inoculated with $P$. niveus in the lab as described below, was aseptically dissected and its infected tissue was included as a positive control. Its tissue was subjected to approximately the same freezing time.

To isolate any $P$. niveus present, tissue samples taken from culled apple fruit were combined with sterile DI $\mathrm{H}_{2} \mathrm{O}(1: 1$, wt/vol). The suspensions were homogenized in sterile stomacher bags (Seward Stomacher 400 circulator) for $2 \mathrm{~min}$ at $230 \mathrm{rpm}$ (Beuchat and Pitt 2001). Next, samples were divided among five 10-ml glass test tubes; four were incubated at $75^{\circ} \mathrm{C}$ for $30 \mathrm{~min}$ in a closed water bath, while the fifth was not heated. The unheated sample was used to estimate the background number of nonheat-resistant fungi present. Duplicate aliquots $(100 \mu \mathrm{l})$ of apple homogenate from each of the four heated test tubes per sample were spread on Petri dishes $(90 \mathrm{~mm})$ of Rose Bengal agar (HIMEDIA). Dilutions from $10^{-1}$ to $10^{-4}$ were made of the unheated samples, and aliquots $(100 \mu \mathrm{l})$ of each dilution were spread on Rose Bengal agar. All Petri plates were incubated at $30^{\circ} \mathrm{C}$ for 1 month (in the dark), and emerging colonies were counted.

Koch's postulates. To test whether $P$. niveus can cause disease in apple, the four steps of Koch's postulates were completed: (i) $P$. niveus isolate $\mathrm{CO} 7$ was isolated from a rotting apple discovered at Cornell Orchards in fall 2014, (ii) P. niveus was grown in pure culture and morphologically and genetically identified (Samson et al. 2000), (iii) the culture of CO7 was used to inoculate healthy apple fruit through a wound and disease symptoms were observed on the inoculated apple fruit using a dissecting microscope (Olympus SZX12), and (iv) the fungus was reisolated from within the lesions of infected apple fruit and confirmed to be $P$. niveus using morphological and genetic approaches.

Inoculation method. In all, 15 Gala and 15 Golden Delicious apple fruit were sanitized ( $30 \mathrm{~s}$ in $70 \%$ ethanol, 2 min in $1 \%$ sodium hypochlorite, and $15 \mathrm{~s}$ in $70 \%$ ethanol) and dried in a biological safety cabinet (Geisler 2013; van der Walt et al. 2010). Following sanitization, apple fruit were numbered and inoculated with $P$. niveus $\mathrm{CO} 7$, which was identified morphologically (Samson et al. 2000), and confirmed through phylogenetic analysis of sequences of the ITS and BenA regions (MG008851 and MG008852).

Colonized toothpicks were used to wound and inoculate mature Gala and Golden Delicious apple fruit. These apple varieties were selected because they are among the top 10 commercial cultivars (US Apple Association 2018). Toothpicks were inoculated with $P$. niveus CO7 as described for Penicillium spp. on apple (van der Walt et al. 2010). Briefly, toothpick pieces (16 mm) were sterilized by autoclaving them five times in DI water, which was replaced between cycles. They were next transferred to potato dextrose broth (Teknova) and autoclaved a final time. Toothpick pieces were aseptically transferred to PDA Petri dishes $(90 \mathrm{~mm})$ containing agar plugs $(5 \mathrm{~mm})$ of a 1-week-old $P$. niveus $\mathrm{CO} 7$ culture. After 2 weeks of incubation $\left(30^{\circ} \mathrm{C}\right.$, in darkness), toothpick pieces were well colonized by $P$. niveus. Control toothpicks were similarly treated, except they were placed on uncolonized PDA Petri dishes $(90 \mathrm{~mm})$. Toothpick pieces were inserted at four points, each halfway between the stem and calyx, to wound the sanitized apple fruit. Two treatments were applied to each apple: (i) two opposite wounds inoculated with P. niveus $\mathrm{CO} 7$ and (ii) two opposite wounds that received control toothpicks. Inoculated Gala and Golden Delicious apple fruit were incubated in separate dark, moist chambers $\left(25^{\circ} \mathrm{C}, \geq 95 \%\right.$ humidity) for 3 weeks.

Disease characterization. To describe the disease symptoms that developed following inoculation with $P$. niveus, Gala and Golden Delicious apple fruit in moist chambers were monitored. Lesions were measured three times a week during the 3 -week incubation period. Using digital calipers (VWR Carbon Fiber Composite), lesion diameters were measured at two perpendicular angles and averaged. To allow for comparisons of each wound over time, individual wounds and apple fruit were tracked with an identification number. To eliminate the possibility of lesion size being influenced by contaminating fungi, any apple fruit that showed signs of contamination during incubation, specifically by Penicillium spp., were removed from the experiment. Several apple fruit of each variety were maintained in moist chambers for an extended period to observe disease symptoms at an advanced stage.

Statistical analysis. Two separate linear mixed-effects models, one at day 7 and one at day 22, were used to test for significant differences between lesion diameters for both treatments (control or inoculated) on both varieties of apple fruit. Fixed effects of apple variety (which was confounded with chamber), treatment, and their interaction were included and a random effect of apple identification number was included, which accounted for the multiple wounds on each apple. These models were executed using the lme 4 and lmerTest packages in $\mathrm{R}$ statistical programming software. Posthoc comparisons were carried out using the lsmeans package. The data were visualized using the ggplot 2 package. 


\section{Results}

Identification and phylogeny. BLASTing (Blastn) of the sequenced regions of CO7 (MG008851 and MG008852) showed that CO7 closely matched $P$. niveus isolates in the NCBI GenBank. The ITS and BenA regions of $\mathrm{CO} 7$ were concatenated and the placement of the isolate within the $P$. niveus clade further confirmed its identity (Supplementary Fig. S1). The P. niveus isolates from New York state orchard soils were morphologically identified, and their identities were supported by phylogenetic analysis (Fig. 1). All isolates from soil clustered with $P$. niveus (B. nivea) that were predominately isolated from spoiled foods (Samson et al. 2009) (Fig. 1).

$P$. niveus in New York orchard soils and culled apple fruit. Fifteen $P$. niveus were isolated from 11 of the 32 New York orchards sampled in 2016 (Table 2). Due to unintentional sampling within several orchards, $P$. niveus was isolated at multiple places in the orchards $5(n=2)$ and $6(n=4)$. This provides evidence that $P$. niveus may be widespread in the soil throughout orchards (Table 2).

After 1 month of incubation at $30^{\circ} \mathrm{C}$, three samples from the notheat-treated culled apple fruit had fungal colonies that were counted. Fungal counts for these samples ranged from 1,000 to 22,000 CFU $\mathrm{ml}^{-1}$. Penicillium spp. were most common on these plates. The other two not-heat-treated culled apple samples showed no fungal growth. Among the five heat-treated samples, only one isolate of a heatresistant mold was found. It was determined not to be a Paecilomyces

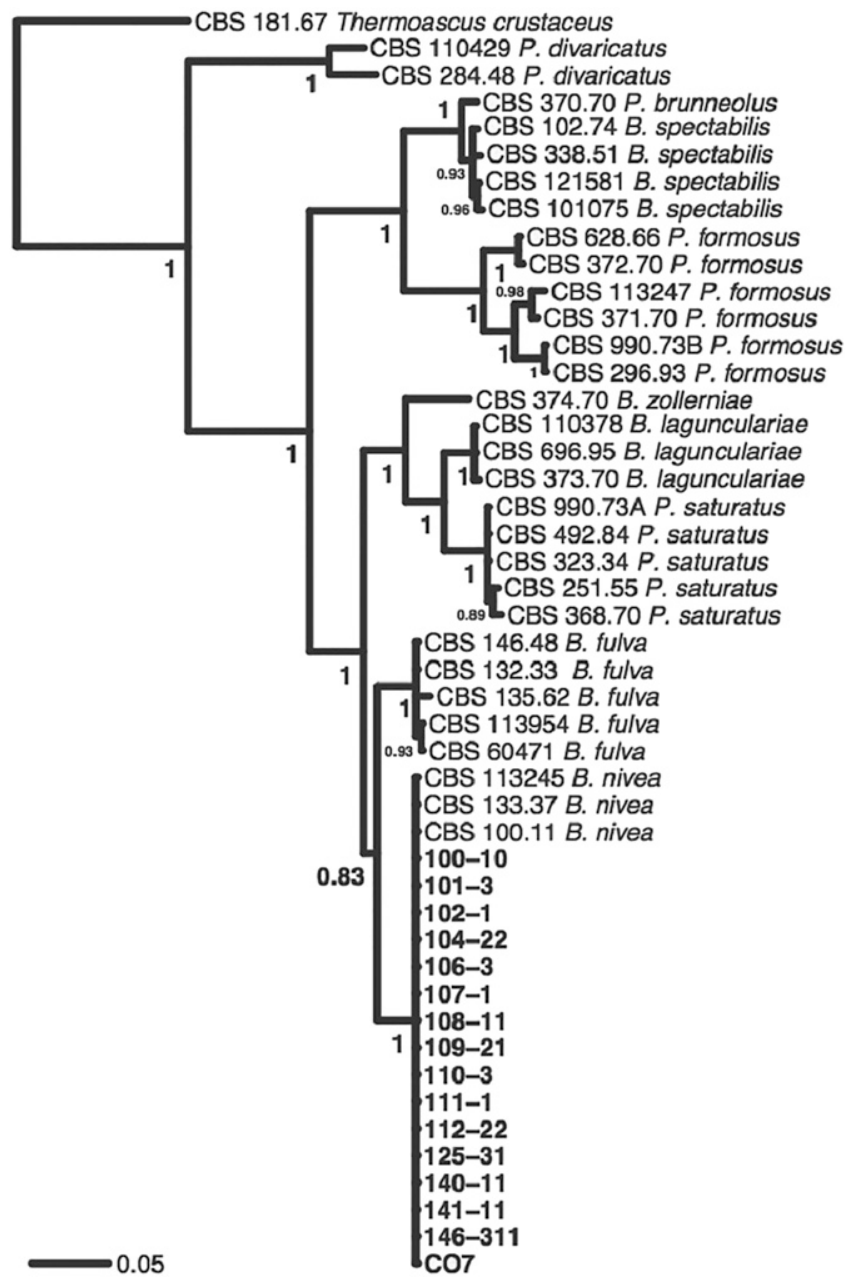

Fig. 1. Consensus topology and branch lengths of partial $\beta$-tubulin sequences of 47 taxa, including Paecilomyces niveus (Byssochlamys nivea) isolates from New York orchards, rooted with Thermoascus crustaceus as an outgroup. Species designations are described by Samson et al. (2009). Tree constructed using MrBayes v3.2.6 with a $\mathrm{K} 80+\mathrm{g}$ model. Support values at nodes represent posterior probabilities, scale bar shows the number of substitutions per site. Isolates from this study are in bold. spp. As expected, $P$. niveus was present in the positive control sample but it was not detected after freezing and heat treatment of that sample.

$P$. niveus causes disease in apple. Isolate $\mathrm{CO}$, taken from rotting apple fruit at Cornell Orchards in 2014, was morphologically identified as $P$. niveus and its identity was supported by phylogenetic analysis. It was grown in pure culture and then used to inoculate healthy apple fruit. After the infected apple fruit began to show symptoms of disease, a fungus was reisolated, grown in pure culture, and identified as $P$. niveus. Koch's postulates were completed by using the fungus to infect healthy apple fruit.

Characterization of Paecilomyces rot. Apple fruit inoculated with $P$. niveus developed circular lesions that radially expanded from the point of inoculation (Fig. 2A and B). Initially, lesions were tan to brown, resembling a bruise. As lesions expanded, they became brown with a lighter brown center. Within 12 days postinoculation, circular lesions enlarged and displayed a series of faint concentric rings, alternating from tan to brown (Fig. 2A), which seemed more visible on Golden Delicious than on Gala apple fruit. Within the infected fruit, medium brown-colored sections of necrotic tissue progressed through the mesocarp toward the endocarp in a tapered cone shape, slightly bowed outward into the surrounding mesocarp (Fig. 2C). This discoloration was firm and spongy and, other than the color, was not easily separable from the healthy tissue (Fig. 2C).

After an extended incubation period (44 days), advanced disease symptoms included the complete discoloration of the apple epidermis to light tan-brown (Fig. 2E and F). The surface of these apple fruit was observed to be sparsely covered by branching white hyphae, concentrated around lenticels in floccose tufts (Fig. 2F). After 44 days, the internal necrotic tissue extended to the cores of both apple varieties (Fig. 2D), which were filled with white mycelium and asci containing ascospores (Fig. 3). At this late stage of necrosis, tissue was marbled in shades of tan and dark brown (Fig. 2D).

Size of $\boldsymbol{P}$. niveus lesions. Wounded apple fruit that were inoculated had lesions that grew rapidly. The average diameters of treatment lesions ( \pm standard error), measured 7 days after inoculation, were $13.3 \pm 0.4 \mathrm{~mm}(n=30)$ and $17.1 \pm 0.3 \mathrm{~mm}(n=30)$ on Gala and Golden Delicious, respectively (Fig. 4). The average diameters of treatment lesions ( \pm standard error), measured 22 days after inoculation, were $47.6 \pm 0.7 \mathrm{~mm}(n=24)$ and $43.2 \pm 0.9 \mathrm{~mm}(n=26)$ on Gala and Golden Delicious, respectively (Fig. 4). The diameter of control lesions remained near the size of the original inoculation wound $(1.8 \mathrm{~mm})$ throughout the study. The average diameters of control lesions ( \pm standard error), measured 7 days after inoculated, were $2.0 \pm 0.3 \mathrm{~mm}(n=30)$ and $2.4 \pm 0.4 \mathrm{~mm}(n=30)$ on Gala and Golden Delicious, respectively. After the 22-day incubation, control lesions ( \pm standard error) increased from the initial 1.8-mm diameter of the toothpick to an average of $3.4 \pm 0.9 \mathrm{~mm}(n=24)$ and $3.2 \pm$ $0.9 \mathrm{~mm}(n=26)$ on Gala and Golden Delicious, respectively (Fig. 4).

Table 2. Origins of Paecilomyces niveus isolates used in this study from soil in New York orchards

\begin{tabular}{lcll}
\hline & & \multicolumn{2}{c}{ Location } \\
\cline { 3 - 4 } Isolate & Orchard & County & \multicolumn{1}{c}{ Town } \\
\hline $100-10$ & 1 & Tompkins & Ithaca \\
$101-3$ & 2 & Clinton & Geneva \\
$102-1$ & 3 & Clinton & Geneva \\
$104-22$ & 4 & Clinton & Peru \\
$106-3$ & 5 & Clinton & Peru \\
$107-1$ & 5 & Clinton & Peru \\
$108-11$ & 6 & Clinton & Peru \\
$109-21$ & 6 & Clinton & Peru \\
$110-3$ & 6 & Clinton & Peru \\
$111-1$ & 6 & Clinton & Peru \\
$112-22$ & 7 & Clinton & Chazy \\
$125-31$ & 8 & Wayne & Sodus \\
$140-11$ & 9 & Dutchess & Shenandoah \\
$141-11$ & 10 & Ulster & New Paltz \\
$146-311$ & 11 & Wayne & Newark \\
\hline
\end{tabular}


The diameters of Paecilomyces rot treatment lesions on both Gala and Golden Delicious were significantly larger than control lesions on days 7 and $22(P<0.0001)$. Although confounded by chamber, treatment lesions on the Gala were smaller than those on Golden Delicious early in the disease $(P<0.0001$, day 7$)$, however, this trend reversed by day 22 , when Gala treatment lesions were larger than those on the Golden Delicious $(P=0.005)$ (Fig. 4). There were no significant differences in control lesion diameters on days 7 or 22 on Gala or Golden Delicious. Over the course of the experiment, six Gala and four Golden Delicious apple fruit were removed from their respective incubation chambers because they showed signs of being colonized by other fungi. Once removed, these apple fruit were excluded from further measurements and statistical analysis.

\section{Discussion}

This is the first report that $P$. niveus can infect apple fruit, which are affected by many other postharvest fungal diseases (Houbraken et al. 2006; Jurick and Cox 2016; Sutton et al. 2014). At least 10 to $15 \%$ of apple fruit are lost during storage because of disease (more in developing markets) (Jurick and Cox 2016). In the United States, postharvest losses cost an estimated $\$ 6.5$ million annually (Jurick and Cox 2016). This work demonstrates that $P$. niveus is commonly found in orchard soils in New York, and can cause a novel postharvest
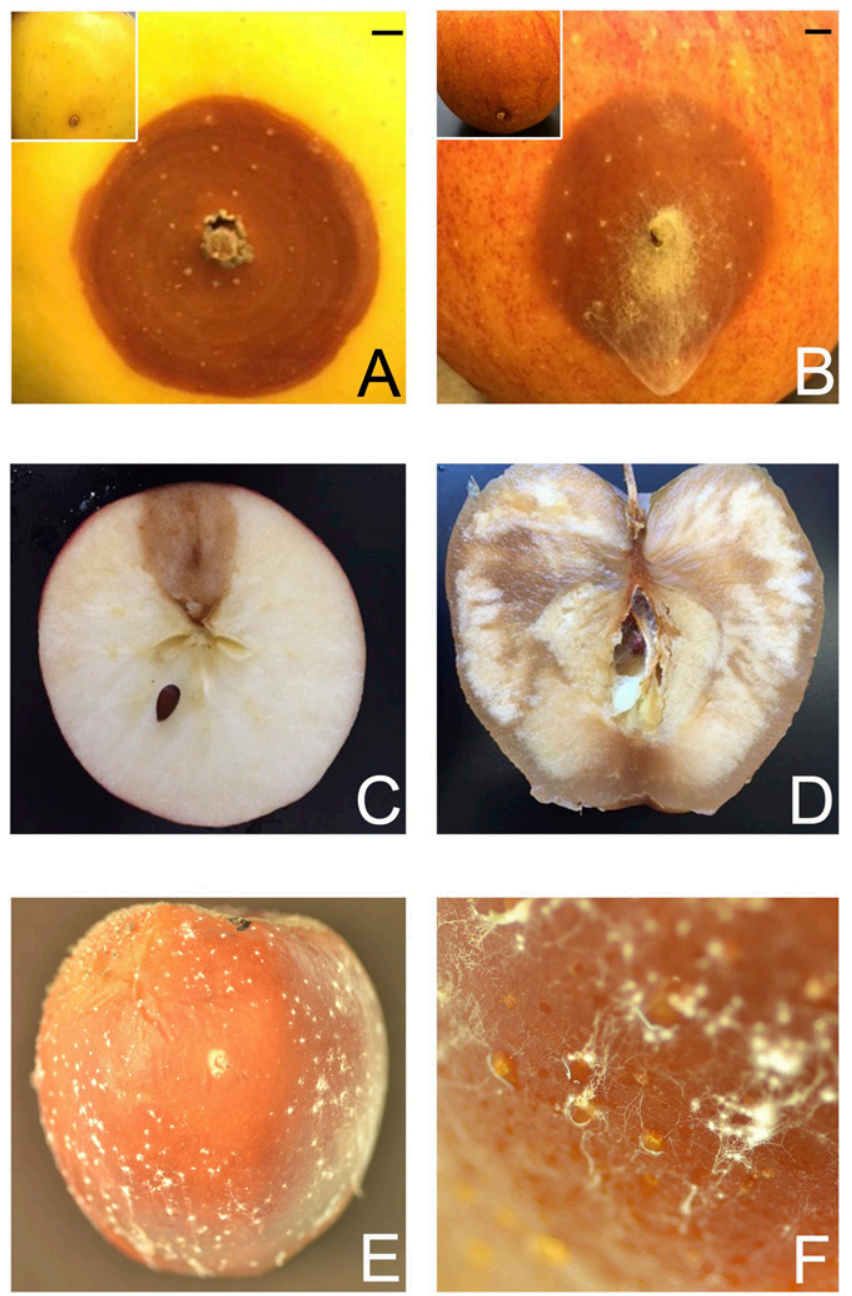

Fig. 2. Disease symptoms caused by Paecilomyces niveus (Byssochlamys nivea) after incubation in dark, moist chambers $\left(25^{\circ} \mathrm{C}, \geq 95 \%\right.$ humidity). External symptoms 12 days postinoculation (dpi) on A, Golden Delicious and B, Gala fruit. Insets show a control apple of each variety. Scale bars are $1.8 \mathrm{~mm}$. C, Cross-section of Gala apple at 12 dpi, showing representative cone-shaped internal rot. D, Longitudinal section of Gala apple, showing internal marbling at 44 dpi. E, Gala apple with advanced Paecilomyces rot at 44 dpi. F, Close-up view of tufts of white mycelia produced on the surface of an infected Gala apple. fruit disease, Paecilomyces rot, on two popular varieties of apple (Piecková et al. 1994; Splittstoesser et al. 1971).

Prior research suggested that soil was the source of food contamination and, indeed, $P$. niveus was present in many New York orchard soils (Table 2). Not only was $P$. niveus in more than a third of the orchards sampled but also isolates were found at multiple points in two of those orchards (Table 2). This finding demonstrates that $P$. niveus is widespread across New York and that it may be common throughout orchards. All $P$. niveus isolates that were found in orchard soils shared a clade with other isolates of this species in the phylogenetic analysis (Fig. 1). Very little is known about the ecology of $P$. niveus and its relatives; however, none of these food spoilage species have been previously described as plant pathogens. Paecilomyces spp. are known for the food spoilage problems they cause in a variety of thermally processed foods but their biology and niches in nature are virtually unstudied. $P$. niveus and some $P$. saturatus are the only species in the genus known to produce patulin (Samson et al. 2009). Perhaps this toxin is responsible for the ability of $P$. niveus to infect apple, because patulin is a virulence factor in apple in the distantly related blue rot pathogen, Penicillium expansum (Ascomycota, Eurotiomycetes, Eurotiales,

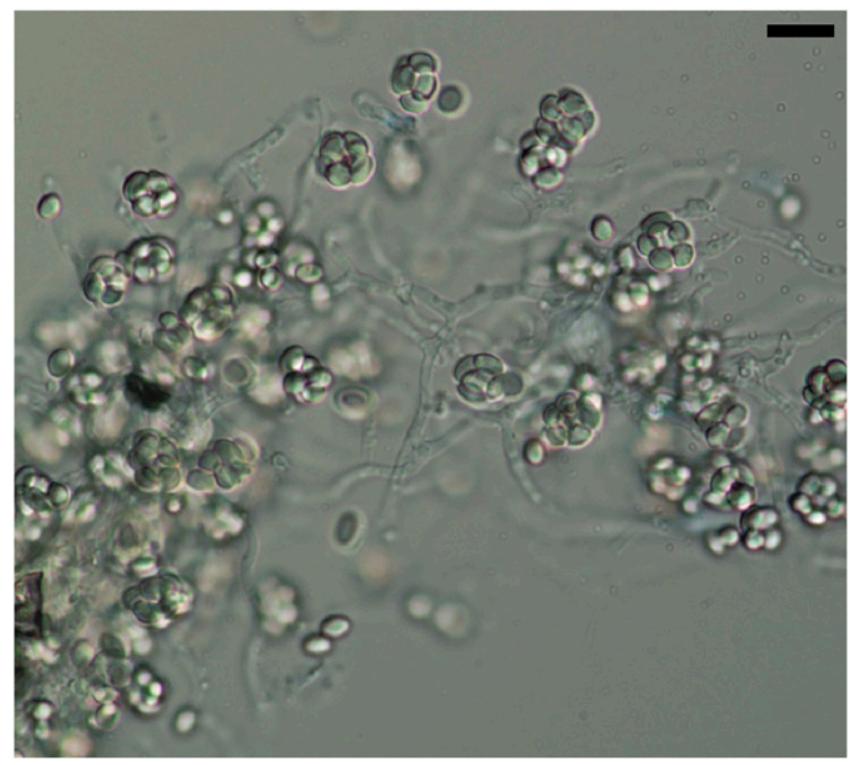

Fig. 3. Representative image of Paecilomyces niveus (Byssochlamys nivea) asci containing ascospores, observed in the cores of infected apple fruit. Scale bar $=$ $10 \mu \mathrm{m}$.

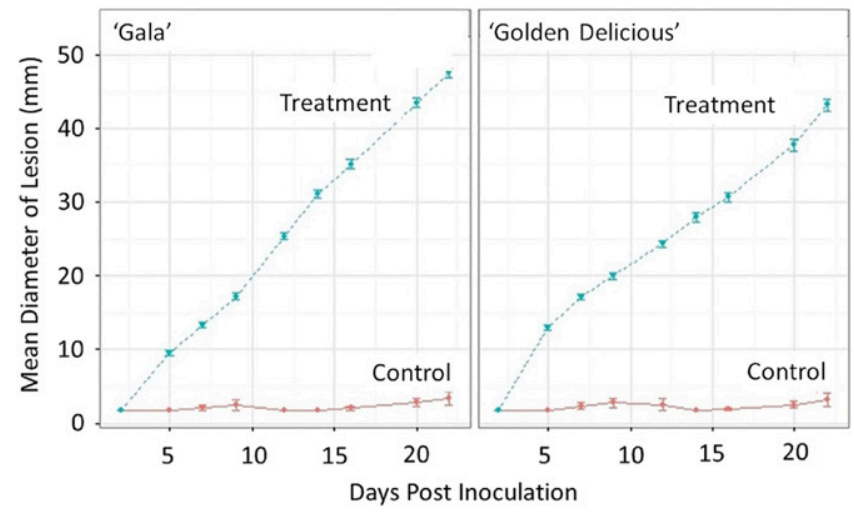

Fig. 4. Increase, over a 22 -day incubation $\left(25^{\circ} \mathrm{C}, \geq 95 \%\right.$ humidity), in the mean diameter of lesions ( \pm 1 standard error) on Gala and Golden Delicious apple fruit inoculated with Paecilomyces niveus (Byssochlamys nivea). Treatment lesions were significantly larger than control lesions on Gala and Golden Delicious at days 7 and $22(P<0.0001)$ 
Trichocomaceae) (i.e., they are in different families) (Baert et al. 2007; Sanzani et al. 2012).

Examining the Paecilomyces niveus isolates found in this study in New York orchard soil and on a decaying apple (CO7) (Table 1) within a phylogenetic context, the $P$. niveus that were isolated were in the same clade as $P$. niveus cultured from food environments (Fig. 1), including pasteurized fruit juice in Europe (CBS 113245) and milk in North America (CBS 133.37) (Samson et al. 2009). P. fulvus spoilage isolates, cultured from bottled fruit and fruit juice (CBS 132.33 and CBS 135.62), were sister to $P$. niveus from orchard soil in our analysis, in agreement with previous work (Fig. 1) (Samson et al. 2009). Because $P$. niveus and $P$. fulvus are close relatives that similarly spoil thermally processed fruit, future studies should evaluate whether $P$. fulvus can infect the fruit that it often spoils.

We hypothesize that infected fruit may be an overlooked source of spoilage of heat-treated apple products, when $P$. niveus survives thermal processing. The harmful practice of using "drops" (fallen apple fruit) must be discouraged. Not only could "drops" passively transport spores in adhering soil particles but also apple fruit may also be wounded and infected through soil contact. The ascospores that develop in infected fruit (Fig. 3) may be able to survive thermal processing. Future work should ask whether fruit with Paecilomyces rot introduce this spoilage organism to thermally processed apple products.

In addition to spoiling food, $P$. niveus produces the mycotoxin patulin in food (Moake et al. 2005; Sant'Ana et al. 2008). Patulin is not eliminated by thermal processing and is a major concern for the apple industry. Patulin acute toxicity includes convulsions, subacute toxicity can include gastrointestinal disorders, and there are concerns that it is carcinogenic (Puel et al. 2010). For these reasons, patulin is limited to $50 \mu \mathrm{g} \mathrm{liter}{ }^{-1}$ by the U.S. Food and Drug Administration, $50 \mathrm{ppb}$ by Health Canada, and 10 to $25 \mu \mathrm{g} \mathrm{liter}^{-1}$ by the European Union in apple juices and other products, of which children are the biggest consumers and most at risk from exposure (Bennett and Klich 2003; Health Canada 2018; Moake et al. 2005; US FDA 2001). Although variety differences between Gala and Golden Delicious were confounded by chamber effects in our study, hints of differences in lesion size and symptoms between the varieties could have implications for contamination. Blue rot lesion diameter positively correlates with patulin accumulation in apple fruit (Sant'Ana et al. 2008). Future research should investigate the accumulation of patulin in apple fruit during the development of Paecilomyces rot and further evaluate disease progression of different apple varieties.

Paecilomyces rot has characteristics that make it difficult to distinguish from other apple diseases: bull's-eye rot, apple ring rot, black rot, and bitter rot. It may have been overlooked because it is masquerading as these other diseases. It causes lesions like those seen in early stages of black rot, caused by Diplodia seriata, and bull's-eye rot or apple ring rot, caused by Neofabraea spp. and Botryosphaeria dothidea, respectively (Sutton et al. 2014). The internal symptoms of Paecilomyces rot resemble bitter rot disease, caused by Colletotrichum gloeosporioides; however, in cross-section, the infected cone-shaped tissue has edges that are more outwardly bowed (U-shaped) (Phillips et al. 2007; Sutton et al. 2014) (Fig. 2C). Paecilomyces rot symptoms, especially on Golden Delicious apple, were reminiscent of bull's-eye rot or black rot symptoms on apple fruit (Sutton et al. 2014). Like both rots, the lesions caused by $P$. niveus were slightly flattened and firm (Fig. 2A and B). Unlike bull's-eye and black rots, $P$. niveus produces no external fruiting bodies such as pycnidia, pseudothecia, or acervuli (Fig. 2F). Although possibly confounded by a chamber effect in our experiment, surface hyphae were more often observed on Gala than Golden Delicious at the site of inoculation; the lenticels on Gala were often colonized with floccose, white mycelia with asci (Fig. 2B). The sparse white surface mycelium noted within Paecilomyces rot lesions (Fig. 2B), distinguished it from bitter rot, which is known for copious quantities of conidia produced on the surface of lesions (Sutton et al. 2014). Compared with postharvest diseases such as blue mold, which has a characteristic musty odor (Sutton et al. 2014), apple fruit infected with $P$. niveus smelled sweet.

Another reason that $P$. niveus has not been previously described as an apple pathogen or isolated from apple storage environments could be due to sampling methods that are biased for fast-growing Penicillium spp. (Amiri and Bompeix 2005). To test this idea, we attempted to isolate $P$. niveus from culled apple fruit. After a recommended heat treatment to reduce other species and activate $P$. niveus ascospores (Houbraken and Samson 2006), no P. niveus was recovered, even from apple tissue known to be infected. This finding may indicate that the temperature used was too high or that combined freezing and heating damaged $P$. niveus. Younger ascospores are known to be less resilient (Bayne and Michener 1979; Dijksterhuis 2007). If $P$. niveus was present in the culled apple fruit at low concentrations, we may have failed to isolate it because of low sample weights. New postharvest sampling approaches, involving the addition of a mild heat treatment to increase germination, might be more successful (Yates et al. 1968).

$P$. niveus is both important and unusual, because it infects apple fruit, produces patulin, causes spoilage, and resists high temperatures, creating multiple risks for processed apple products. To avert food safety problems caused by $P$. niveus, apple products may benefit from higher processing temperatures. More research is needed on the incidence of Paecilomyces rot, to trace a pathway from infected fruit to spoiled processed foods, and to investigate patulin production in infected apple fruit.

\section{Acknowledgments}

We thank Cornell Cooperative Extension agents, apple consultants, and orchard owners for their help in soil sampling; the Cornell University Orchards for their support of this work; E. Mudrak of the Cornell Statistical Consulting Unit for her assistance with data analyses; J. Gonzalez for his assistance with phylogenetic analyses; and $\mathrm{K}$. Cox for his advice on comparable diseases.

\section{Literature Cited}

Agostino, M. 2012. Introduction to the BLAST Suite and BLASTN. Pages 47-71 in: Practical Bioinformatics. G. Almond, ed. Garland Science, Taylor and Francis Group LLC, New York.

Altschul, S. F., Gish, W., Miller, W., Myers, E. W., and Lipman, D. J. 1990. Basic local alignment search tool. J. Mol. Biol. 215:403-410.

Amiri, A., and Bompeix, G. 2005. Diversity and population dynamics of Penicillium spp. on apples in pre- and postharvest environments: Consequences for decay development. Plant Pathol. 54:74-81.

Baert, K., Devlieghere, F., Flyps, H., Oosterlinck, M., Ahmed, M. M., Rajković A., Verlinden, B., Nicolaï, B., Debevere, J., and De Meulenaer, B. 2007. Influence of storage conditions of apples on growth and patulin production by Penicillium expansum. Int. J. Food Microbiol. 119:170-181.

Bayne, H. G., and Michener, H. D. 1979. Heat resistance of Byssochlamys ascospores. Appl. Environ. Microbiol. 37:449-453.

Bennett, J. W., and Klich, M. 2003. Mycotoxins. Clin. Microbiol. Rev. 16:497-516.

Beuchat, L. R., and Pitt, J. I. 2001. Detection and enumeration of heat-resistant molds. Pages 216-222 in: Compendium of Methods for the Microbiological Examination of Foods. F. P. Downes and K. Ito, eds. The American Public Health Association, Washington, DC.

Beuchat, L. R., and Rice, S. L. 1979. Byssochlamys spp. and their importance in processed fruits. Adv. Food Res. 25:237-288.

Beuchat, L. R., and Toledo, R. T. 1977. Behaviour of Byssochlamys nivea ascospores in fruit syrups. Trans. Br. Mycol. Soc. 68:65-71.

Brown, A. H. S., and Smith, G. 1957. The genus Paecilomyces Bainier and its perfect stage Byssochlamys Westling. Trans. Br. Mycol. Soc. 40:17-89, IN2-IN3.

Castresana, J. 2000. Selection of conserved blocks from multiple alignments for their use in phylogenetic analysis. Mol. Biol. Evol. 17:540-552.

Darriba, D., Taboada, G. L., Doallo, R., and Posada, D. 2012. jModelTest 2: More models, new heuristics and parallel computing. Nat. Methods 9:772.

Dijksterhuis, J. 2007. Heat-resistant ascospores. Pages 101-117 in: Food Mycology: A Multifaceted Approach to Fungi and Food. J. Dijksterhuis and R. A. Samson, eds. CRC Press, Boca Raton, FL.

Dombrink-Kurtzman, M. A., and Engberg, A. E. 2006. Byssochlamys nivea with patulin-producing capability has an isoepoxydon dehydrogenase gene (idh) with sequence homology to Penicillium expansum and P. griseofulvum. Mycol. Res. 110:1111-1118.

Edgar, R. C. 2004. MUSCLE: Multiple sequence alignment with high accuracy and high throughput. Nucleic Acids Res. 32:1792-1797.

Geisler, B. M. 2013. Commodity Apple Profile. Online publication. Agriculture Marketing Resource Center. https://www.agmrc.org/commodities-products/ fruits/apples/commodity-apples/

Grant, W. D. 2004. Life at low water activity. Philos. Trans. R. Soc. Lond. 359: 1249-1267.

Health Canada. 2018. List of Contaminants and other Adulterating Substances in Foods. Online publication. https://www.canada.ca/en/health-canada/services/ food-nutrition/food-safety/chemical-contaminants/contaminants-adulteratingsubstances-foods.html\#fn_tlb1-ref 
Houbraken, J., and Samson, R. A. 2006. Standardization of methods for detecting heat resistant fungi. Pages 107-111 in: Advances in Food Mycology. A. D. Hocking, J. I. Pitt, R. A. Samson, and U. Thrane, eds. Springer, New York.

Houbraken, J., and Samson, R. A. 2017. Current taxonomy and identification of foodborne fungi. Curr. Opin. Food Sci. 17:84-88.

Houbraken, J., Samson, R. A., and Frisvad, J. C. 2006. Byssochlamys: Significance of heat resistance and mycotoxin production. Adv. Exp. Med. Biol. 571:211-224.

Houbraken, J., Varga, J., Rico-Munoz, E., Johnson, S., and Samson, R. A. 2008. Sexual reproduction as the cause of heat resistance in the food spoilage fungus Byssochlamys spectabilis (anamorph Paecilomyces variotii). Appl. Environ. Microbiol. 74:1613-1619.

Huelsenbeck, J. P., Larget, B., and Alfaro, M. E. 2004. Bayesian phylogenetic model selection using reversible jump Markov chain Monte Carlo. Mol. Biol. Evol. 21:1123-1133.

Jurick, W. M., and Cox, K. D. 2016. Pre- and postharvest fungal apple diseases. Pages 1-12 in: Achieving Sustainable Cultivation of Apples. K. Evans, ed. Burleigh Dodds Science Publishing Limited, Cambridge, U.K.

King, A. D., Michener, H. D., and Ito, K. A. 1969. Control of Byssochlamys and related heat-resistant fungi in grape products. Appl. Microbiol. 18:166-173.

Li, W., Cowley, A., Uludag, M., Gur, T., McWilliam, H., Squizzato, S., Park, Y. M., Buso, N., and Lopez, R. 2015. The EMBL-EBI bioinformatics web and programmatic tools framework. Nucleic Acids Res. 43:W580-W584.

Moake, M. M., Padilla-Zakour, O. I., and Worobo, R. W. 2005. Comprehensive review of patulin control methods in foods. Compr. Rev. Food Sci. Food Saf. 4:8-21.

Paradis, E., Claude, J., and Strimmer, K. 2004. APE: Analyses of phylogenetics and evolution in R language. Bioinformatics 20:289-290.

Phillips, A. J. L., Crous, P. W., and Alves, A. 2007. Diplodia seriata, the anamorph of "Botryosphaeria" obtusa. Fungal Divers. 25:141-155.

Piecková, E., Bernát, D., and Jesenská, Z. 1994. Heat resistant fungi isolated from soil. Int. J. Food Microbiol. 22:297-299.

Puel, O., Galtier, P., and Oswald, I. P. 2010. Biosynthesis and toxicological effects of patulin. Toxins (Basel) 2:613-631.

Ronquist, F., Teslenko, M., Van Der Mark, P., Ayres, D. L., Darling, A., Höhna, S., Larget, B., Liu, L., Suchard, M. A., and Huelsenbeck, J. P. 2012. MrBayes 3.2: Efficient Bayesian phylogenetic inference and model choice across a large model space. Syst. Biol. 61:539-542

Salomão, B. D. C. M., Muller, C., Couto do Amparo, H., and Falcão de Aragão, G. M. 2014. Survey of molds, yeast and Alicyclobacillus spp. from a concentrated apple juice productive process. Braz. J. Microbiol. 45:49-58.

Samson, R. A., Hoekstra, E. S., Frisvad, J. C., and Filtenborg, O. 2000. Ascomycetes. Pages 26-52 in: Introduction to Food-and Airborne Fungi. R. A. Samson and E. S. Hoekstra, eds. Centaalbureau voor Schimmelcultures, Utrecht, The Netherlands.

Samson, R. A., Houbraken, J., Varga, J., and Frisvad, J. C. 2009. Polyphasic taxonomy of the heat resistant ascomycete genus Byssochlamys and its Paecilomyces anamorphs. Persoonia 22:14-27.

Sant'Ana, A. D. S., Rosenthal, A., and de Massaguer, P. R. 2008. The fate of patulin in apple juice processing: A review. Food Res. Int. 41:441-453.
Sanzani, S. M., Reverberi, M., Punelli, M., Ippolito, A., and Fanelli, C. 2012. Study on the role of patulin on pathogenicity and virulence of Penicillium expansum. Int. J. Food Microbiol. 153:323-331.

Schoch, C. L., Seifert, K. A., Huhndorf, S., Robert, V., Spouge, J. L., Levesque, C. A., Chen, W., Bolchacova, E., Voigt, K., Crous, P. W., and Miller, A. N. 2012 Nuclear ribosomal internal transcribed spacer (ITS) region as a universal DNA barcode marker for fungi. Proc. Natl. Acad. Sci. USA 109:6241-6246.

Snini, S. P., Tadrist, S., Laffitte, J., Jamin, E. L., Oswald, I. P., and Puel, O. 2014 The gene PatG involved in the biosynthesis pathway of patulin, a food-borne mycotoxin, encodes a 6-methylsalicylic acid decarboxylase. Int. J. Food Microbiol. 171:77-83.

Splittstoesser, D. F., Kuss, F. R., and Harrison, W. 1970. Enumeration of Byssochlamys and other heat-resistant molds. Appl. Microbiol. 20:393-397.

Splittstoesser, D. F., Kuss, F. R., Harrison, W., and Prest, D. B. 1971. Incidence of heat resistant molds in eastern orchards and vineyards. Appl. Microbiol. 21:335-337.

Sutton, T. B., Aldwinckle, H. S., Agnello, A. M., and Walgenbach, J. F., eds. 2014 Compendium of Apple and Pear Diseases and Pests, 2nd ed. American Phytopathological Society, St. Paul, MN.

Taniwaki, M. H., Hocking, A. D., Pitt, J. I., and Fleet, G. H. 2009. Growth and mycotoxin production by food spoilage fungi under high carbon dioxide and low oxygen atmospheres. Int. J. Food Microbiol. 132:100-108.

Taniwaki, M. H., Hocking, A. D., Pitt, J. I., and Fleet, G. H. 2010. Growth and mycotoxin production by fungi in atmospheres containing $80 \%$ carbon dioxide and 20\% oxygen. Int. J. Food Microbiol. 143:218-225.

Tournas, V. 1994. Heat-resistant fungi of importance to the food and beverage industry. Crit. Rev. Microbiol. 20:243-263.

US Apple Association. 2018. Popular varieties. Online publication. http://usapple. org/all-about-apples/apple-varieties/

US FDA. 2001. Apple Juice, Apple Juice Concentrates, and Apple Juice Products-Adulteration with Patulin. Compliance policy guidance for FDA staff. Sect. 510.150. Online publication. U.S. Food and Drug Administration. https://www.fda.gov/ICECI/ComplianceManuals/CompliancePolicyGuidanceManual/ ucm074427.htm

Vaidya, G., Lohman, D. J., and Meier, R. 2011. SequenceMatrix: Concatenation software for the fast assembly of multi-gene datasets with character set and codon information. Cladistics 27:171-180.

van der Walt, L., Spotts, R. A., Visagie, C. M., Jacobs, K., Smit, F. J., and McLeod, A. 2010. Species associated with preharvest Wet Core Rot in South Africa and their pathogenicity on apple. Plant Dis. 94:666-675.

Visagie, C. M., Houbraken, J., Frisvad, J. C., Hong, S. B., Klaassen, C. H. W., Perrone, G., Seifert, K. A., Varga, J., Yaguchi, T., and Samson, R. A. 2014. Identification and nomenclature of the genus Penicillium. Stud. Mycol. 78:343-371.

White, T. J., Bruns, S., Lee, S., and Taylor, J. 1990. Amplification and direct sequencing of fungal ribosomal RNA genes for phylogenetics. Pages 315-322 in: PCR Protocols: A Guide to Methods and Applications. M. A. Innis, D. H. Gelfand, J. J. Sninsky, and T. J. White, eds. Academic Press, New York.

Yates, A. R., Seaman, A., and Woodbine, M. 1968. Ascospore germination in Byssochlamys nivea. Can. J. Microbiol. 14:319-325. 